Textures and Microstructures, 1988, Vol. 10, pp. 67-75

Reprints available directly from the publisher

Photocopying permitted by license only

C) 1988 Gordon and Breach Science Publishers Inc.

Printed in the United Kingdom

\title{
The Development of Dislocation Structure and Texture in Rolled Copper (001)[110] Single Crystals
}

\author{
M. WRÓBEL, S. DYMEK, M. BLICHARSKI and \\ S. GORCZYCA
} Department of Metallurgy, Academy of Mining and Metallurgy, Kraków,
Poland

(Received October 24, 1987)

The initial orientation has split into two equally strong symmetric orientations:

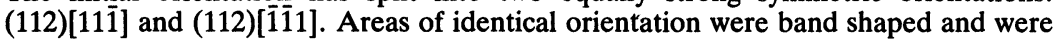
called deformation bands. Up to $60 \%$ reduction, deformation occurs by slip on one plane (one from two possible) in two directions. This leads to the appearance of deformation bands with transition bands between them. Due to such deformation the initial orientation rotates around transverse direction towards the end-orientation $\{112\}\langle 111\rangle$. Due to rotation of the crystallographic lattice with deformation, the Taylor factor $M$ changes as well, and it causes the activation of two not coplanar slip systems which stabilize the end-orientations $\{112\}\langle 111\rangle$. Such a sequence of the slip systems activation was concluded from the agreement of the calculated and experimental pole figures. The electron microscopy investigations showed that first shear bands formed due to the activation of these new slip systems.

KEY WORDS: Copper, Single crystal, Rolling deformation, Pole figures, Electron microscopy, Selected area diffraction.

\section{INTRODUCTION}

Recently much attention has been paid to the problems concerning the development of microstructure and texture during high strains. From the investigations carried out on polycrystal materials it has been concluded that the dislocation microstructure is determined 
by many factors which include: type of the crystallographic lattice, stacking fault energy, initial grain size, method of deformation, magnitude and temperature of deformation and strain rate (Hatherly, 1982). It was also found that the grain orientation affects the dislocation microstructure (Dymek et al. 1985). It is well known that description of the microstructure and texture development during deformation in polycrystalline materials is far from being satisfactory because of the uncertainty concerning the stress field at any given point in the material. To avoid these difficulties single crystals have been examined (Bauer et al. 1977, Mori et al. 1981, Malin et al. 1981). Among the numerous investigation of single crystals only few attempts have been made to study the relationship between microstructure and texture development during rolling.

The aim of the present investigation is to establish a relationship between the microstructure and texture development in copper single crystals with metastable orientation (001)[110].

\section{Material and specimen preparation}

The material used was copper single crystals with the orientation (001)[110]. Bars of the size $8 \times 30 \times 100 \mathrm{~mm}$ were rolled in both direction by reversing end to end between passes. According to Bauer et al. (1977) and Asbeck et al. (1978) the $l / h$ coefficient characterizing the geometry of the rolling gap was kept between 1.1 and 3 during each pass $(l$ is the projected length of contact between the roll and the material; $h$ is the mean thickness of the sample). The cumulative rolling reductions were $40 \%, 60 \%, 80 \%, 90 \%$ and $95 \%$. Optical and electron metallography was performed for all rolling reductions on the longitudinal specimens in the central parts of the rolled bar. Specimens whose thicknesses were less than $3 \mathrm{~mm}$ were electroplated with copper. The metallographic specimens were electrolytically polished and etched in a solution of $33 \% \mathrm{HNO}_{3}$ and $67 \% \mathrm{CH}_{3} \mathrm{OH}$. The texture was evaluated by the Schulz backreflection technique. The $\{111\}$ pole figures were obtained for the centre layer of the specimens parallel to the rolling plane. Using the computer model RC (Latas et al. 1987) the theoretical $\{111\}$ pole figures were calculated. From a comparison of calculated and experimental pole figures one can draw conclusions about slip systems acting during deformation. 


\section{Results and discussion}

The texture development in the examined copper single crystals is very similar to that reported by Bauer et al. (1977) for copper single crystals with the same orientation. As was expected, in the centre layer of the crystal the initial orientation was not stable on deformation by rolling. The original crystal orientation split into two equally strong symmetric end orientations (112)[111] and (112)[1̄11] (Figure 1). This splitting represents a $\pm 35^{\circ}$ rotation of the initial orientation into opposite directions around (transverse direction) TD.

The optical micrograph shown in Figure 2 represents the microstructure after $95 \%$ reduction but it is characteristic for all examined deformations. The splitting of the specimen was visible after $40 \%$ deformation. The striations represent traces of the $\{111\}$ planes. The mean angles between the $\{111\}$ plane traces and the rolling direction (RD) were $\pm 20^{\circ}, \pm 25^{\circ}, \pm 30^{\circ}, \pm 35^{\circ}$ for deformations $40 \%, 60 \%, 80 \%$ and $90 \%$ respectively. They correspond to the same degrees of rotation of the initial orientation on the pole figures.

The $\{111\}$ planes revealed by etching on the metallographic specimens are not the active slip planes but they correspond to plane traces referred to slip systems 5 and 6 (Figure 3). This is in agreement with a paper of Kohlhoff et al. (1981).

Electron microscopy investigations show that deformation bands were built with dislocation bands (dislocation rich layers) parallel to

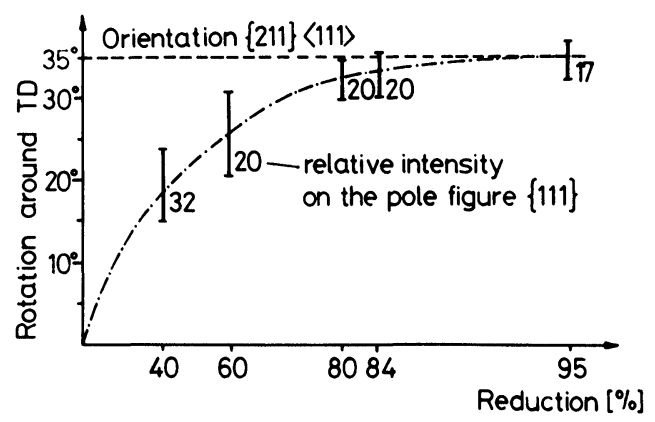

Figure 1 Degree of rotation around TD of initial (001)[110] orientation into $\{112\}\langle 111\rangle$ vs. strain. 


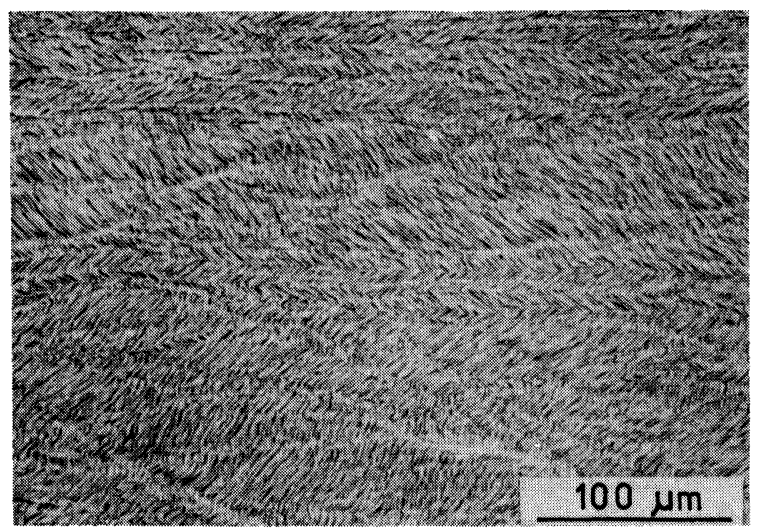

Figure 2 Microstructure after $95 \%$ deformation. Optical micrograph. The centre layers of the specimen. The longer edge is parallel to the rolling direction.

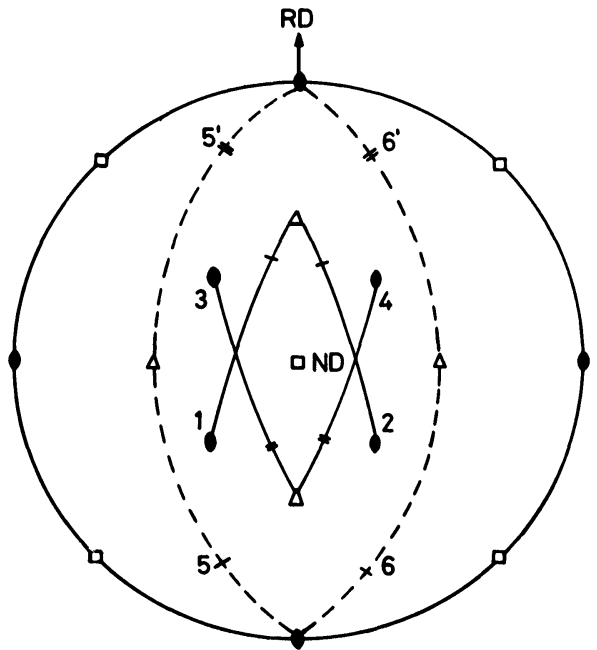

Slip system operated in the bands:

$$
\begin{aligned}
& +-\mathrm{nr} 1 \\
& -+\mathrm{nr} 2
\end{aligned}
$$

Figure 3 Slip systems operating in the (001)[110] crystal. 
the active slip planes. These dislocation bands were $0.1-1 \mu \mathrm{m}$ thick after $40 \%$ reduction and with increasing strain the bands got thinner and thinner and they reached a thickness of $0.08-0.45 \mu \mathrm{m}$ after $95 \%$ deformation. In the adjacent deformation bands the angles between the dislocation bands change from $70^{\circ}$ after $40 \%$ reduction to $40^{\circ}$ after $80 \%$ reduction. Such a change of angles between dislocation bands with deformation is proof that they are parallel to the slip planes in systems 1,2 and 3, 4. The thickness of the transition bands decrease with deformation. After $40 \%$ reduction they were $1-4 \mu \mathrm{m}$ wide (Figure 4). After $80 \%$ reduction the transition bands degenerate sometimes into a boundary with a sudden orientation change (Figure 5). The microstructure of the

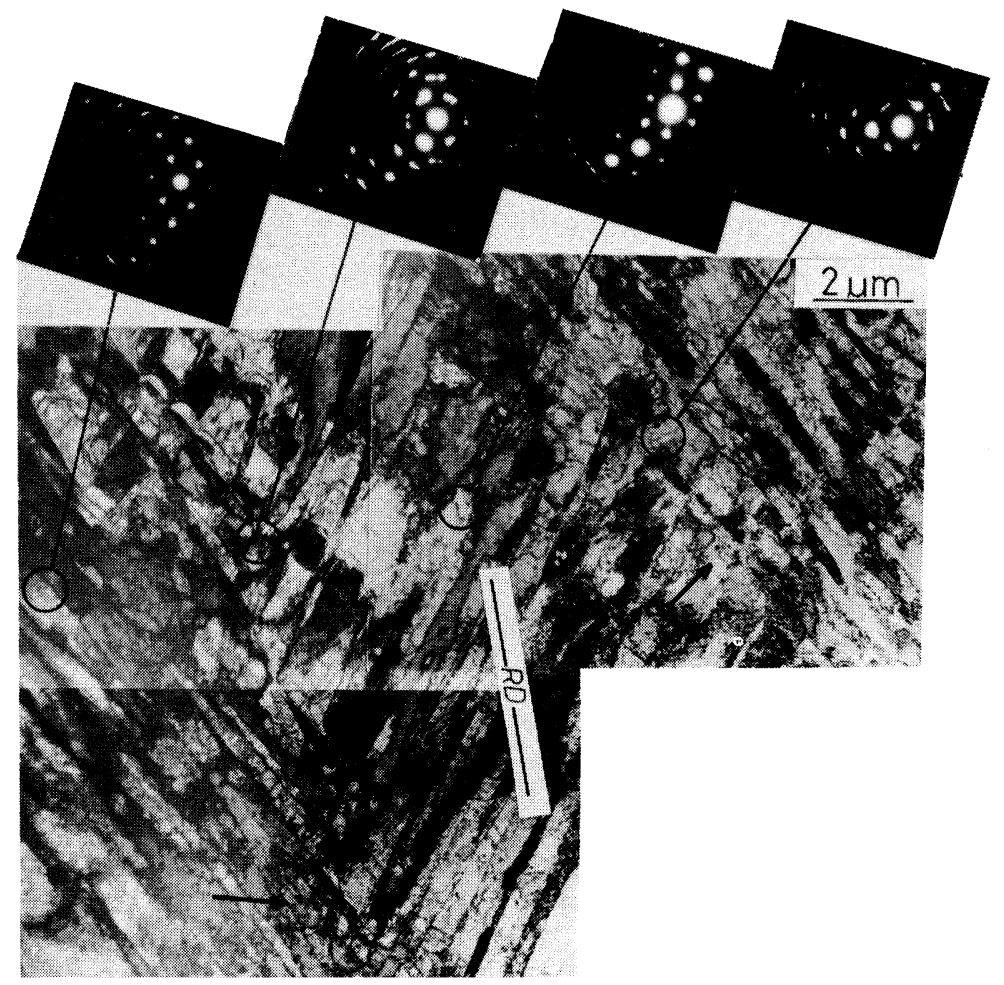

Figure 4 Transition bands (marked by arrows) built up with interpenetrating dislocation rich layers; $40 \%$ deformation. 


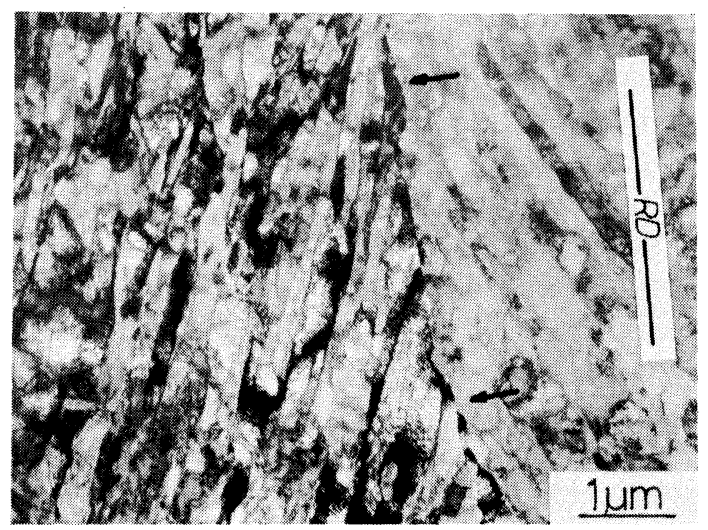

Figure 5 The narrow transition band (marked by arrows) similar to a grain boundary; $80 \%$ deformation.

observed transition bands is very similar to that observed by Wilbrandt and Haasen (1980) in copper single cyrstals deformed by tension, by Baker and Martin (1983) in rolled copper single crystals and by Dymek and Blicharski (1984) in ferritic stainless steels.

First microbands (Figure 6) appear after 60\% reduction. They were approx. $0.1 \mu \mathrm{m}$ thick. The observed microbands were parallel to the $\{111\}$ planes and were inclined at an angle of $\sim 30^{\circ}$ to the RD. The density of the microbands increased with increasing strain and after $80 \%$ reduction microband clusters are observed which, in

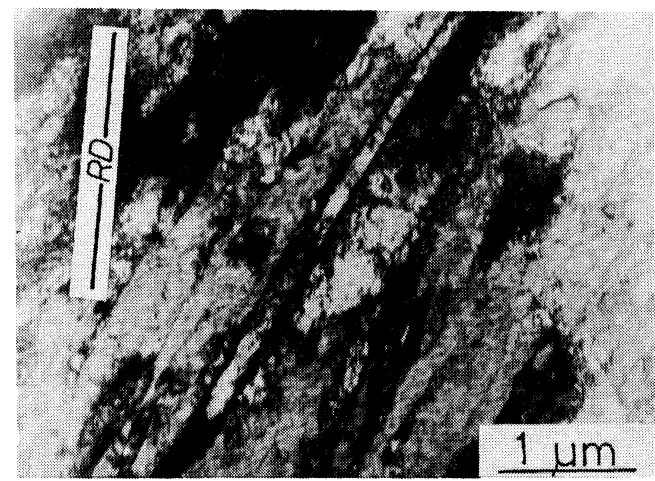

Figure 6 Microband in a specimen deformed $60 \%$. 

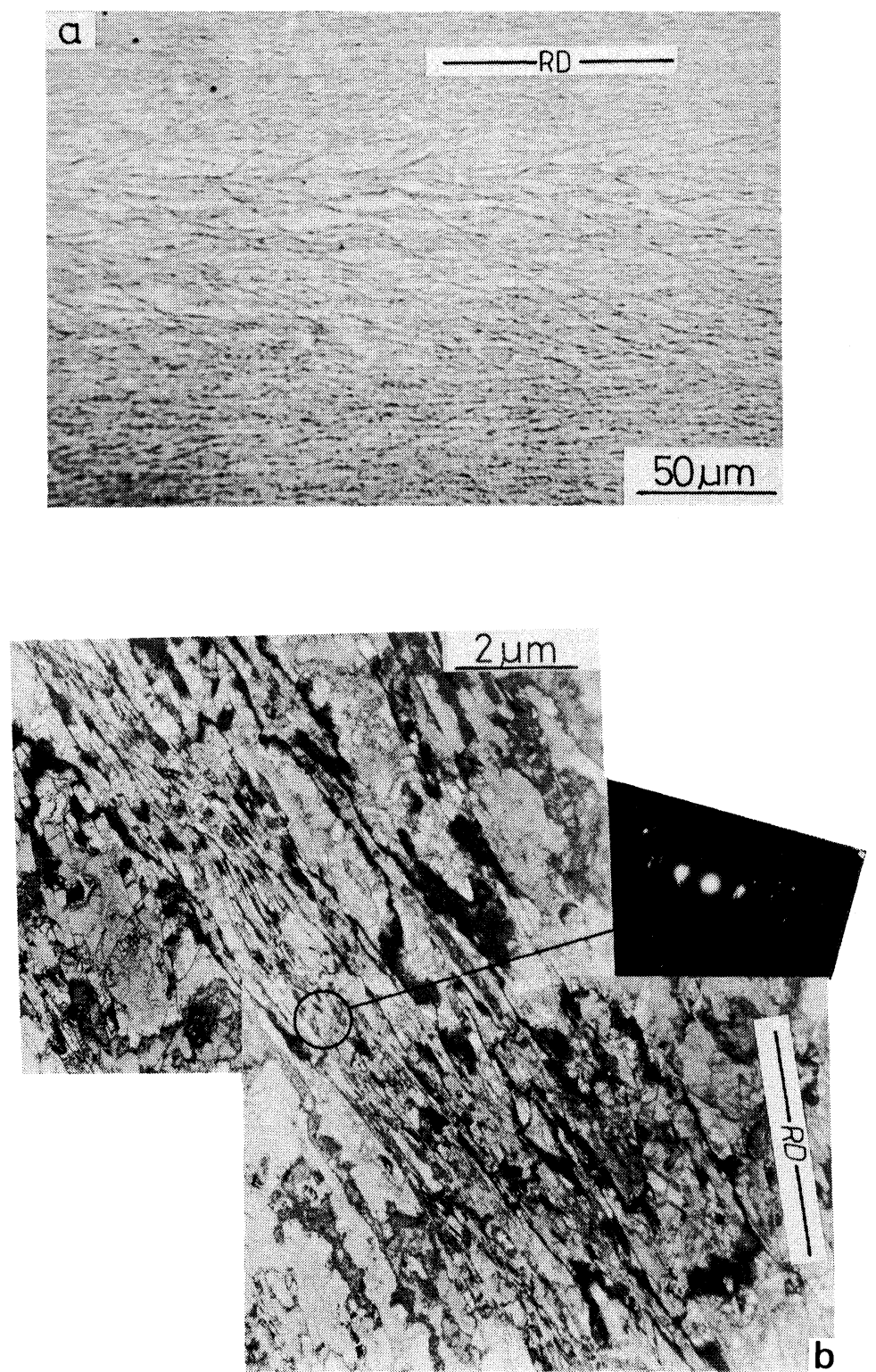

Figure 7 Shear bands: a) optical micrograph (phase contrast); 95\% deformation, b) electron micrograph, $80 \%$ deformation. 
this case, form shear bands. The average angle between the shear bands and the RD was approx. $\pm 30^{\circ}$ but independently of the magnitude of deformation, the greatest value of that angle was approximately $35^{\circ}$ and was very near to the angle between traces of slip planes from systems 5 and 6 and RD. The smallest value of angle decreased with deformation from $25^{\circ}$ after $80 \%$ to $10^{\circ}$ after 95\% reduction. The observed shear bands were usually $2-3 \mu \mathrm{m}$ thick. A characteristic feature was that shear bands were observed only in regions with the end orientation $\{211\}\langle 111\rangle$ (Figure 7).
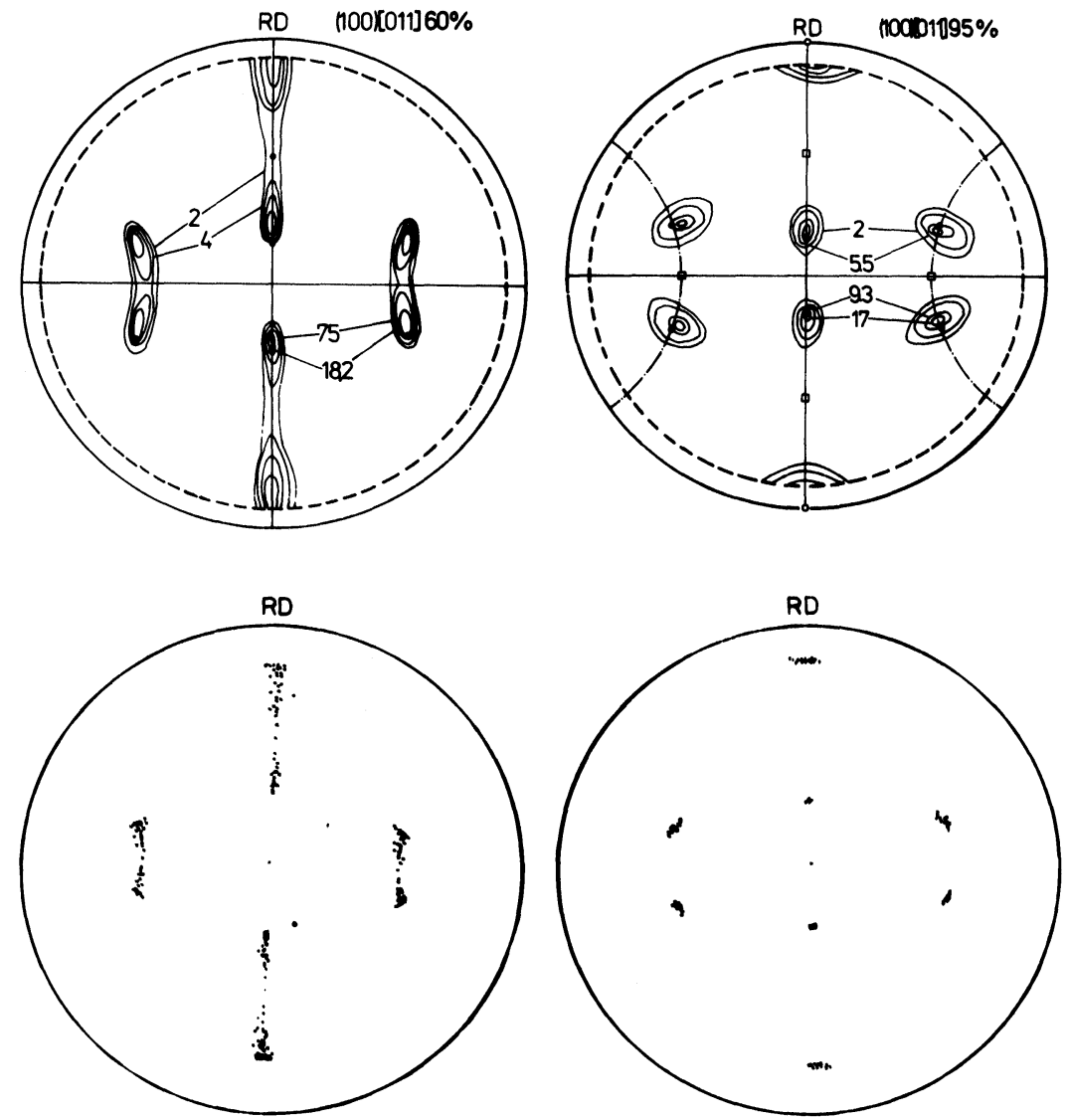

Figure 8 Experimental and calculated textures of a crystal with initial orientation (001)[110]. 
The crystallographic relationships and results obtained suggest the following pattern of structure development. Up to $60 \%$ reduction, deformation occurs alternatively by slip in systems 1 and 2 or 3 and 4 (Figure 3) (only one slip plane with two slip directions is active). Such a deformation mode leads to the appearance of deformation bands with transition bands between them. Due to such deformation, the initial orientation rotates around TD toward

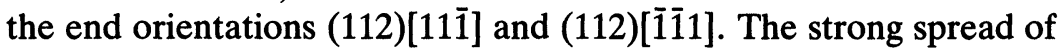
orientation by rotation around TD visible on pole figures after $40 \%$ and $60 \%$ reduction (Figure 8 ) is due to the distribution of the orientation of deformation bands in addition to changes of the orientation in initially wide transition bands. It seems that the volume fraction of the transition bands decreases with increasing deformation because their thickness decreases. Simultaneously, more and more deformation bands attain the end orientation $\{211\}\langle 111\rangle$. This can be seen on the pole figure (Figure 8) where the end orientation becomes sharper with increasing strain. Due to the rotation of the crystallographic lattice with deformation, the Taylor factor $M$ changes as well and it causes the activation of two new not coplanar slip systems (5 and 6 or $5^{\prime}$ and $6^{\prime}$ ) which stabilize the end-orientation $\{211\}\langle 111\rangle$. Activation of new noncoplanar slip systems leads to microband and shear band formation. Both microbands and shear bands are initially parallel to the traces of the active slip systems and then their inclination to the RD decreases due to their rotation with deformation. Further increase of deformation makes the volume fraction of shear bands also increase.

\section{References}

Asbeck, H. and Mecking, H. (1978). Mat. Sci. Eng. 34, 111.

Baker, J. and Martin, J. W. (1983). Met. Sci. 17, 459.

Bauer, R., Mecking, H. and Lücke, K. (1977). Mat. Sci. Eng. 27, 163.

Dymek, S. and Blicharski, M. (1984). Scripta Met. 18, 99.

Dymek, S. and Blicharski, M. (1985). Z. Metallkunde 76, 777.

Hatherly, M., 6th Int. Conf. on Strength of Metals and Alloys, ed. R. C. Gifkins, Pergamon Press, Oxford 1982, p. 1181.

Kohlhoff, D. G., Hirsch, J., Schlippenbach, U. and Lücke, K., Proc. of ICOTOM 6 The Iron and Steel Institute of Japan, Tokyo 1981, vol. 1, p. 489.

Latas, W., Wróbel, M. and Gorczyca, S. (1987). Archiv. of Metallurgy 32, 529.

Malin, A., Huber, J. and Hatherly, M. (1981). Z. Metallkunde 72, 310.

Mori, K. and Nakayama, Y., Proc. of ICOTOM 6, The Iron and Steel Institute of Japan, Tokyo 1981, vol. 1, p. 327.

Wilbrandt, P. J. and Haasen P. (1980). Z. Metallkunde 71, 273. 